\title{
Nitriding in cathodic cage of stainless steel AISI 316: Influence of sample position
}

\author{
R.R.M. de Sousa ${ }^{\text {a }}$, F.O. de Araújo ${ }^{\text {b, } *}$, J.A.P. da $\operatorname{Costa}^{c}$, T. Dumelow ${ }^{\text {c }}$, R.S. de Oliveira ${ }^{d}$, C. Alves, Jr. ${ }^{d}$ \\ ${ }^{a}$ Grupo de Pesquisa em Materiais e Metrologia, CEFET-PI, Departamento de Mecânica, Teresina, PI, Brazil \\ ${ }^{\mathrm{b}}$ Departamento de Ciências Exatas e Naturais, UFRSA, Mossoró, RN, Brazil \\ ${ }^{\mathrm{c}}$ Departamento de Física, UERN, Campus Central, Mossoró, RN, Brazil \\ d LabPlasma, Departamento de Física, UFRN, Campus Universitário, 59072-970 Natal, RN, Brazil
}

\section{A R T I C L E I N F O}

\section{Article history:}

Received 22 September 2008

Received in revised form

5 April 2009

Accepted 26 April 2009

\section{Keywords:}

Cathodic cage plasma nitriding

Austenitic stainless steel

Uniformity layer

\begin{abstract}
A B S T R A C T
Cathodic cage plasma nitriding is a new growth technique based on multiple hollow cathode effects. The samples are kept at a floating potential inside a cage that acts as a cathode and shields the samples from the cathodic potential. The aim of this work is to perform a systematic study of the properties of nitrided layers as a function of the distance from the nitriding sample surface to the cage wall using this technique. Cylindrical austenitic stainless steel AISI 316 samples were placed in different positions on an alumina plate inside the cathodic cage. The nitrided samples were characterized by optical microscopy, X-ray diffraction and microhardness measurements. The results show that the temperature inside the cage is nearly uniform and that the nitrided layers possess good physical properties and uniformity. Therefore, the differences in the nitrided layer thicknesses obtained at different positions must be due to particle flow reaching the sample surface, depending on how far the sample is from the cage walls.
\end{abstract}

(C) 2009 Elsevier Ltd. All rights reserved.

\section{Introduction}

All types of stainless steel are of great use in engineering due to their high corrosion resistance, although they possess low wear resistance and reduced hardness. These two last properties are significantly improved through ionic plasma nitriding [1-3]. As is well known, when the nitriding of austenitic stainless steel is carried out at temperatures higher than $723 \mathrm{~K}$, layers having high wear resistance and surface hardness are produced, while the corrosion resistance diminishes significantly due to precipitation of chromium nitrite, with a consequent reduction of the chromium content in the matrix. In contrast, when the nitriding is carried out at temperatures lower than $723 \mathrm{~K}$ a phase supersaturated with nitrogen, called expanded austenitic or S-phase, which possesses high hardness and wear resistance as well as a great resistance to corrosion, is formed [4,5].

In this study the objective is to identify the influence of the nitriding sample position inside the cathodic cage on the nitriding layer properties. Cathodic cage plasma nitriding is a new technique, based on the hollow cathode effect due to the plasma confinement in each hole of the cage, on which the samples are placed on an isolating plate and surrounded by a metallic cage assembled with holes (Fig. 1).

\footnotetext{
* Corresponding author. Tel.: +55 843315 1799; fax: +55 8433151798 .

E-mail address: odolbert@yahoo.com.br (F.O. de Araújo).
}

Using this technique, we intend to obtain nitrided layers with microhardness and corrosion resistance as good as those of layers obtained by conventional ionic plasma nitriding, but with some improvements, such as greater thickness, better uniformity, higher hardness and the elimination of the so-called border effect [6-8].

\section{Materials and methods}

The material used in this study was annealed austenitic stainless steel 316 (microhardness $240 \mathrm{HV}$ ), provided by Villares Metals SA. Its nominal elemental atomic composition is shown in Table 1.

The previously annealed austenitic stainless steel AISI 316 samples were machined in cylindrical form, ground with 320,400 , 600 and 1200 mesh grinding papers and polished on a felt disc with 0.3 and $1 \mu \mathrm{m}$ diamond suspensions. They were then ultrasonically cleaned in an acetone bath, before being placed in the nitriding chamber. The nitriding system consists of a power source (maximum tension $1500 \mathrm{~V}$, current $2 \mathrm{~A}$ ) and a cylindrical stainless steel vacuum chamber ( $40 \mathrm{~cm}$ in diameter and $40 \mathrm{~cm}$ in height). We used a cathodic cage made from stainless steel 316 of thickness $0.8 \mathrm{~mm}$, diameter $112 \mathrm{~mm}$, and height $25 \mathrm{~mm}$, width $8 \mathrm{~mm}$ diameter holes uniformly distributed, with a distance of $9.2 \mathrm{~mm}$ between centres of adjacent holes. With this configuration the plasma is formed on the cathodic cage, which works as the cathode, and not directly on the surface of the samples [6,7].

The samples were pre-treated with hydrogen for $20 \mathrm{~min}$ at a temperature of $573 \mathrm{~K}$ and a pressure of $200 \mathrm{~Pa}$ in order to 

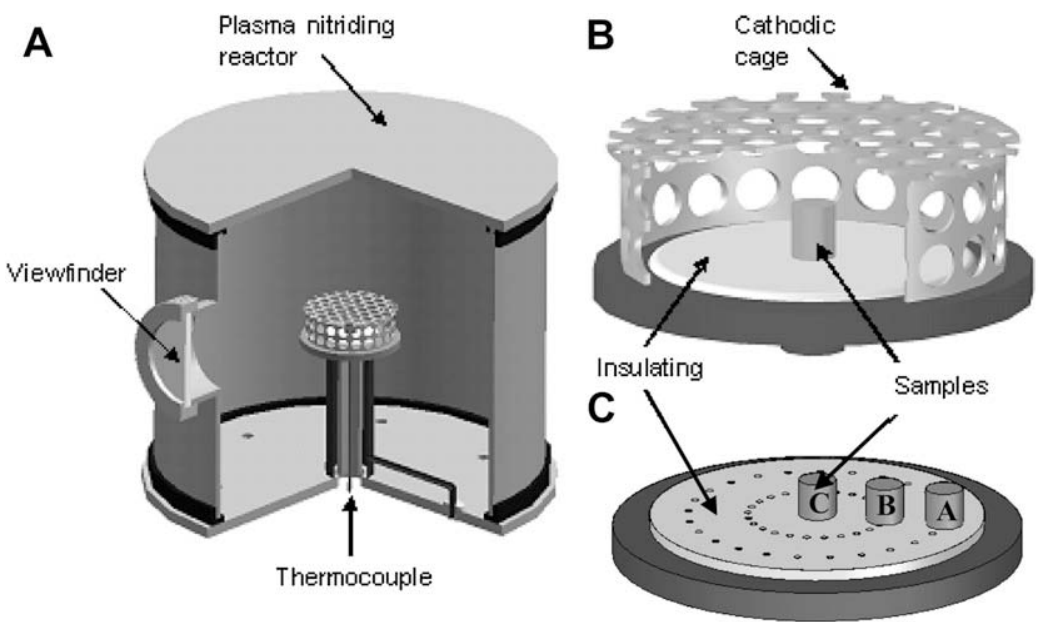

Fig. 1. (A) The reactor scheme of plasma ionic nitride, (B) configuration of cathode cage used onto process and (C) spatial distribution of the samples nitrided at 250 Pa.

Table 1

Elemental composition of the austenitic stainless steel AISI 316 (at.\%).

\begin{tabular}{llllllllll}
\hline $\mathrm{Cr}$ & $\mathrm{Ni}$ & $\mathrm{Mo}$ & $\mathrm{C}$ & $\mathrm{Mn}$ & $\mathrm{Si}$ & $\mathrm{P}$ & $\mathrm{S}$ & $\mathrm{Al}$ & $\mathrm{Fe}$ \\
\hline $16-18 \%$ & $10-14 \%$ & $2-3 \%$ & $0.08 \%$ & $2 \%$ & $1 \%$ & $0.04 \%$ & $0.03 \%$ & $0.02 \%$ & Balance \\
\hline
\end{tabular}

Table 2

Layer thicknesses and microhardness of the nitrided layers as a function of the work pressure and sample position inside the cage ( $5 \mathrm{~h}, 723 \mathrm{~K}$ and $80 \% \mathrm{~N}_{2}+20 \% \mathrm{H}_{2}$ ).

\begin{tabular}{lllc}
\hline Pressure [Pa] & Sample position & $\begin{array}{l}\text { Nitriding layer } \\
\text { thickness }[\mu \mathrm{m}]\end{array}$ & $\begin{array}{c}\text { Microhardness } \\
{\left[\mathrm{HV}_{0,1}\right] \pm 8.0 \%}\end{array}$ \\
\hline 250 & A & $28.2 \pm 0.7$ & 1115 \\
& B & $24.4 \pm 0.8$ & 1305 \\
120 & C & $22.2 \pm 1.0$ & 1213 \\
& A & $61.9 \pm 1.0$ & 978 \\
& B & $56.7 \pm 1.5$ & 953 \\
& C & $51.4 \pm 1.6$ & 931 \\
\hline
\end{tabular}

eliminate contaminants such as oxides and/or grease/fat adsorbed on the surface. They were then treated under the following conditions: $5 \mathrm{~h}$ at a temperature of $723 \mathrm{~K}$ at pressures of 120 and $250 \mathrm{~Pa}$ in nitriding atmosphere mixture of $80 \% \mathrm{~N}_{2} / 20 \% \mathrm{H}_{2}$, with a flow rate of $20 \mathrm{sccm}$, regulated with a mass flow controller. After the nitriding process, the samples were cooled down slowly inside the chamber to a temperature of $353 \mathrm{~K}$ to prevent oxidation. Then they were prepared for metallography analysis and etched in a solution containing $50 \% \mathrm{HCl}+25 \% \mathrm{HNO}_{3}+25 \% \mathrm{H}_{2} \mathrm{O}$ and Beraha II.

The composition and texture of the samples were analyzed using X-ray diffraction (XRD). These analyses were carried out using $\mathrm{Cu} \mathrm{K} \alpha$ (wave length: $0.154 \mathrm{~nm}$ ) and $\mathrm{Mo} \mathrm{K} \alpha(\lambda=0.07094 \mathrm{~nm})$ lines operated at $40 \mathrm{KV}$ using a Shimadzu XRD-6000 instrument. An optical microscope (Olympus BX60M) and SEM (Philips, model XL 30 ESEM) were used to observe and measure the thickness of the layers and to evaluate their texture and uniformity. Microhardness profiles of the top surface of the nitrided samples were measured, using an instrument Pantec 1000 with pyramidal indentor using load of $100 \mathrm{~g}$, in order to evaluate the uniformity of the layers.

\section{Results and discussion}

The surface microhardness and layer thickness measurement data for samples treated in different positions (A, B and C -Fig. 1c), under pressures of 120 and $250 \mathrm{~Pa}$, are presented in Table 2 .
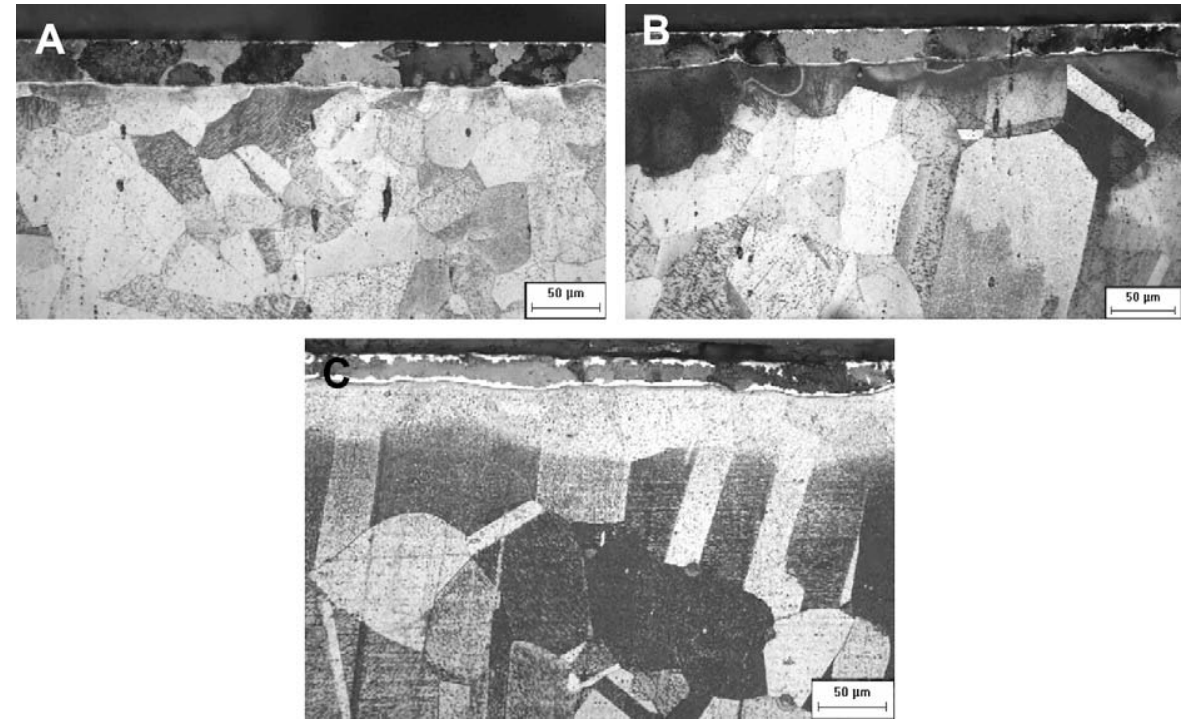

Fig. 2. Micrographs of samples treated under a pressure of $250 \mathrm{~Pa}$ at temperatures of $723 \mathrm{~K}$ during $5 \mathrm{~h}$ placed at different positions (A), (B) and (C). 


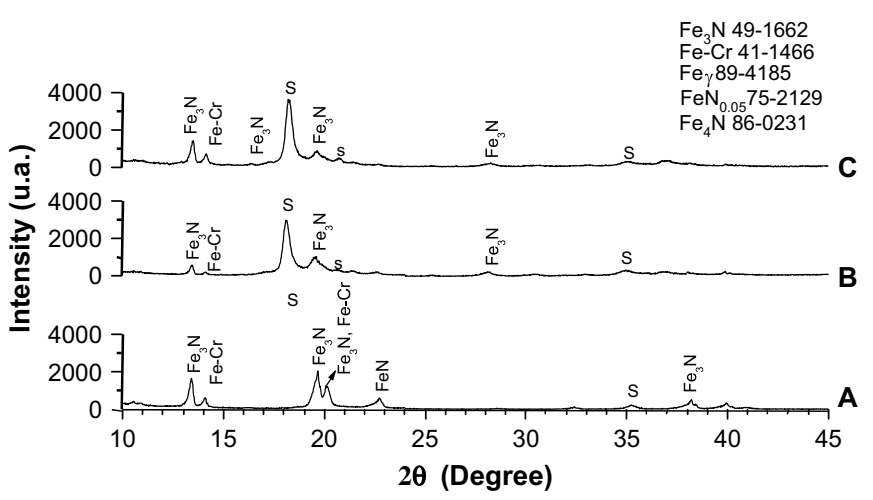

Fig. 3. X-ray diffractograms [Mo $\mathrm{K} \alpha(\lambda=0.07094)$ ] for samples nitrided at $723 \mathrm{~K}$, during $5 \mathrm{~h}$ in a pressure of $250 \mathrm{~Pa}$, placed at different positions $(\mathrm{A}, \mathrm{B}, \mathrm{C})$ inside of the cathodic cage.

These data show that samples treated by the cathodic cage technique under the low pressure (120 Pa) develop nitrided layers thicker than the samples treated at the pressure of $250 \mathrm{~Pa}$, in agreement with previous works [6,7]. At a lower working pressure we have an increase in the mean free path of the ion particles that reach the holes of the cathodic cage walls, increasing the sputtering rate, and consequently the particle flow, and obtaining higher deposition efficiency, resulting on thicker layers than those obtained from conventional ionic nitriding. This confirms that, in the cathodic cage technique, which is based on the hollow cathodic effect, deposition is the predominant process.

In the present technique, species once deposited on the sample surface are not subsequently sputtered from it. This contrasts with the case of conventional ionic plasma nitriding in which there is a competition between sputtering from the sample surface and diffusion. In the conventional technique, for a nitriding temperature of $623 \mathrm{~K}$, the sputtering rate is $1.62 \mu \mathrm{m} / \mathrm{h}$ [10]. Thus nitriding for $5 \mathrm{~h}$ results in a layer of $8.10 \mu \mathrm{m}$ thinner than that obtained using the cathodic cage technique. For temperatures of $723 \mathrm{~K}$ and $873 \mathrm{~K}$ the sputtering rate from the sample is $3.0 \mu \mathrm{m} / \mathrm{h}$ [11], so that on nitriding for $5 \mathrm{~h}$ the thickness difference is $15.0 \mu \mathrm{m}$.

The present results (Table 2 ) show that there is a slight increase in the layer thicknesses for the samples placed in positions nearer to the cage walls (positions $B$ and $C$ ) due to the higher species flow rate, produced by the superposition of the species flow from the top and lateral cage walls.

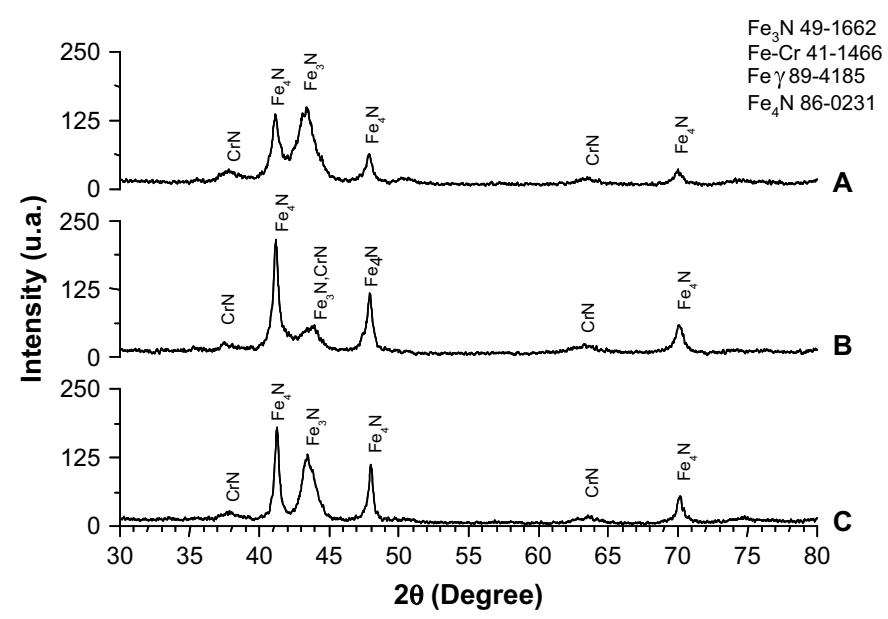

Fig. 5. X-ray diffractograms [Cu $\mathrm{K} \alpha$ (wave length: $0.154 \mathrm{~nm}$ )] for samples nitrided at $723 \mathrm{~K}$, during $5 \mathrm{~h}$ under a pressure of $120 \mathrm{~Pa}$, placed at different positions $(\mathrm{A}, \mathrm{B}, \mathrm{C})$ inside of the cathodic cage.

The micrographs for the samples nitrided under a pressure of $250 \mathrm{~Pa}$ (Fig. 2) show some differences, especially when we compare the layer formed in the sample placed on the position $\mathrm{C}$ with the others. For the sample placed at position $C$, the micrograph shows white regions at the interface of the deposited layer with the substrate and at the layer surface. This is an indication of the presence of the S-phase [4,5,9,14-17]. The other samples do not show such pronounced regions.

The X-ray diffractograms presented in Fig. 3 show that for the case of thicker nitrided layers (positions $A$, near the edge of the sample table) there is a predominance of iron nitrides [12]. This is due to the fact that the nitriding species, which originate in the cathodic cage walls reach the sample surface with larger energy and intensity than in the case of the samples nearer to the centre of the sample table.

The micrographs presented in Fig. 4 show that, for the samples treated under the pressure of $120 \mathrm{~Pa}$, the nitrided layers do not present white regions at the layer/substrate interface and at the layer surface, in contrast with the samples nitrided under a pressure of $250 \mathrm{~Pa}$. This shows that the expanded austenitic is absent, and is confirmed by the X-ray analysis (Fig. 5). The absence of the Sphase is probably responsible for the systematic reduction in the surface hardness (Table 2) when compared with the samples treated at a pressure of $250 \mathrm{~Pa}$.
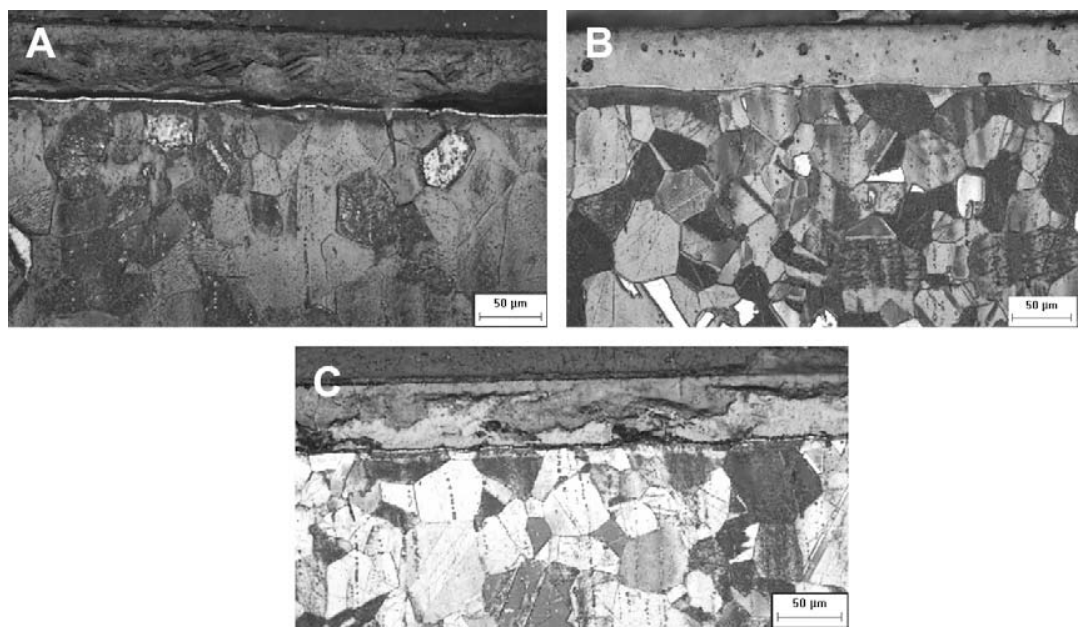

Fig. 4. Micrographs of samples treated under pressure of $120 \mathrm{~Pa}$ at the temperatures of $723 \mathrm{~K}$ during $5 \mathrm{~h}$ placed at different positions (A), (B) and (C). 
The X-ray diffractograms presented in Fig. 5, for a pressure of $120 \mathrm{~Pa}$, do not present intensity variation of the peaks characteristic of iron nitride $\left[\gamma^{\prime}-\mathrm{Fe}_{4} \mathrm{~N}\right]$. This is an indication that a thermal gradient in the interior of the cathodic cage is insignificant, since any increase in the treatment of temperature should cause an increase of the intensity of the iron nitride peaks, $\gamma^{\prime}-\mathrm{Fe}_{4} \mathrm{~N}[13]$.

\section{Conclusions}

We have shown that the cathodic cage technique is efficient for the growth of uniform, resistant, hard, thick layers for any spatial distribution of samples. Since the technique is based on a multiple hollow cathode process, we have established most suitable treatment process parameters for effective growth.

Samples nitrided at lower pressure $(120 \mathrm{~Pa})$ present thicker nitrided layers and lower hardness than the samples nitrided at $250 \mathrm{~Pa}$. Moreover for samples nitrided under the same working pressure, but placed at different positions inside the cathodic cage, the nitrided layers are thicker for samples nearer to the cage.

\section{Acknowledgements}

This work has been partially supported by the Brazilian agencies, CAPES and CNPq and the material was supplied by Villares Metals SA.

\section{References}

[1] Zhang ZL, Bell T. Surface Engineering 1995;1(2):131.

[2] Menthe E, Rie K-T. Surface and Coatings Technology 1999;116-119: 199-204.

[3] Cheng Zhao, Li CX, Dong H, Bell T. Surface and Coatings Technology 2005;191:195-200.

[4] Menthe E, Bulak A, Olfe J, Zimmermann A, Rie K-T. Surface and Coatings Technology 2000;133-134:259-63.

[5] Li CX, Bell T. Corrosion Science 2004;46:1527-47.

[6] Sousa RRM, Alves Jr C, Araujo FO, Costa JAP, Ribeiro KJB, Sousa RS. Surface and Coatings Technology 2006;201:2450-4.

[7] Sousa RRM, Araujo FO, Ribeiro KJB, Mendes MWD, Costa JAP, Alves Jr C. Materials Science and Engineering A, Structural Materials: Properties, Microstructure and Processing 2007;465:223-7.

[8] Macak ED, Munz WD, Rodemburg JM. Journal of Applied Physics 2003; 94:2829-36.

[9] Li CX, Georges J, Li XY. Surface Engineering 2002;18(6):453-8.

[10] Moller W, Parascandola S, Telbizova T, Günzel R, Richter E. Surface and Coatings Technology 2001;136:73-9.

[11] Dimitrov VI, D’haen J, Knuyt G, Quacyhacgens C, Stals LM. Surface and Coatings Technology 1998;99:234-41.

[12] Borgioli F, Fossati A, Galvanetto E, Bacci T, Pradelli G. Surface and Coatings Technology 2006;200:5505-13.

[13] Sun Y, Li CX, Bell T. Journal of Materials Science 1999;34:4793-802.

[14] Oliveira AM, Riofano RMM, Casteletti LC, Temiliosi GF, Bento CAS. Effect of the temperature of plasma nitriding in AISI 316L austenitic stainless steel. Revista Brasileira de Vácuo 2003;22(2):63-6.

[15] Mitchell DRG, Attard DJ, Collins GA, Short KT. Surface and Coatings Technology 2003;165:107-18.

[16] Thaiwatthana S, Li XY, Dong H, Bell T. Comparison studies on properties of nitrogen and carbon "S" phase on low temperature plasma alloyed AISI 316 stainless steel. Surface Engineering 2002;18(6).

[17] Dearnley PA. Corrosion wear response of "S" coated 316L. Surface Engineering 2002;18(6):429-32. 